\title{
Una experiència amb entorns telemàtics cooperatius a la classe de química
}

\author{
Gregorio Jiménez Valverde. IES Mercè Rodoreda. L'Hospitalet de Llobregat. gijimene2@xtec.net \\ Anna Llitjós i Viza. Grup de recerca educativa ECEM (Ensenyament de les Ciències i Educació Mediambi- \\ ental). Universitat de Barcelona
}

L'objectiu d'aquesta comunicació és descriure una experiència innovadora sobre treball cooperatiu on-line duta a terme amb els estudiants del CFGS de Química Ambiental utilitzant un entorn telemàtic cooperatiu gratuït "Synergeia". També es posa a l'abast del professorat uns detallats tutorials d'aquesta eina telemàtica per tal que la puguin utilitzar a les seves classes $i$ aprofitar-ne el potencial educatiu.

Com a professionals de l'educació, hem de preparar el nostre alumnat per viure en la Societat de la Informació i, per tant, les Tecnologies de la Informació i la Comunicació (TICs) no poden quedar al marge de la nostra tasca docent. Les TICs juguen un paper fonamental en la reestructuració del procés educatiu ja que, entre d'altres motius, constitueixen per elles mateixes un volum important de currículum tècnic, científic i cultural i, per tant, impliquen un conjunt de tècniques imprescindibles per participar en el nostre entorn cultural. En aquest escrit, descrivim l'aplicació docent d'un recurs telemàtic que afavoreix el treball cooperatiu on-line entre estudiants: el Synergeia.

\section{El Synergeia i el treball cooperatiu}

El Synergeia és l'aplicació en el món docent de la plataforma d'espais compartits BSCW (Jiménez i Llitjós, 2005a). És un entorn telemàtic, flexible i gratuït que possibilita el treball cooperatiu a persones que no coincideixen a l'espai o en el temps i no requereix cap requisit especial (no és cap programa informàtic). S'hi pot accedir des de qualsevol ordinador connectat a Internet, independentment del seu sistema operatiu, mitjançant qualsevol navegador; només s'ha d'indicar-hi la pàgina web on es troba allotjat el servidor del Synergeia. Els centres educatius poden aconseguir gratuïtament el programari necessari per muntar un servidor propi o bé poden fer servir el servidor públic del FIT.
L'aprenentatge cooperatiu és una tècnica pedagògica centrada en l'estudiant i alguns dels avantatges de la seva aplicació adequada són la millora del rendiment dels estudiants i l'increment de la seva responsabilitat i de la seva participació activa en el procés d'aprenentatge. També estan descrites una millora de l'autoestima, una millor integració de l'alumnat, cada cop més heterogeni, i unes interrelacions més positives, ja que el fet d'haver de realitzar un projecte comú potencia el desenvolupament d'habilitats interpersonals, com són la negociació o la presa de decisions (Johnson i Johnson, 1999).

L'entorn Synergeia és un recurs de recursos. És un sistema obert i dinàmic, que no resta fix sinó que pot evolucionar o canviar sempre que es considera necessari, i en això se centra una part important del seu interès per la seva aplicació en el món de la docència. Permet, dins un marc comú, dissenys específics per a cada assignatura, adaptacions a la gran diversitat de l'alumnat i d'estratègies d'aprenentatge, aspectes molt importants i significatius en l'actualitat.

El Synergeia controla un nombre d'espais compartits de treball, visualitzats com a carpetes de grup i de curs, als quals s'accedeix amb un nom d'usuari/ària i contrasenya. Una carpeta pot contenir diferents objectes, com ara documents, imatges, adreces d'Internet, discussions sobre assumptes determinats, informació de contacte de la resta de membres, etc. El professorat gestiona els permisos dels usuaris a les diferents carpetes. 


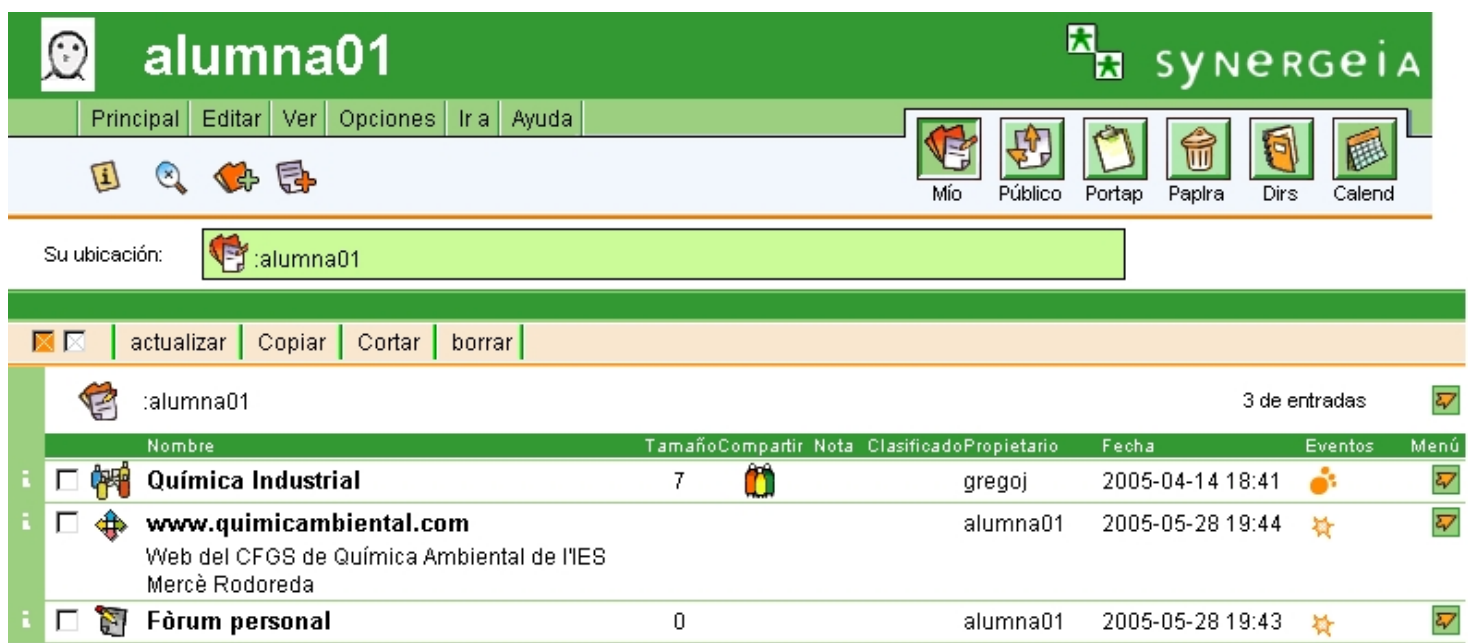

Figura 1. Pàgina d'inici de la usuària "alumna01"

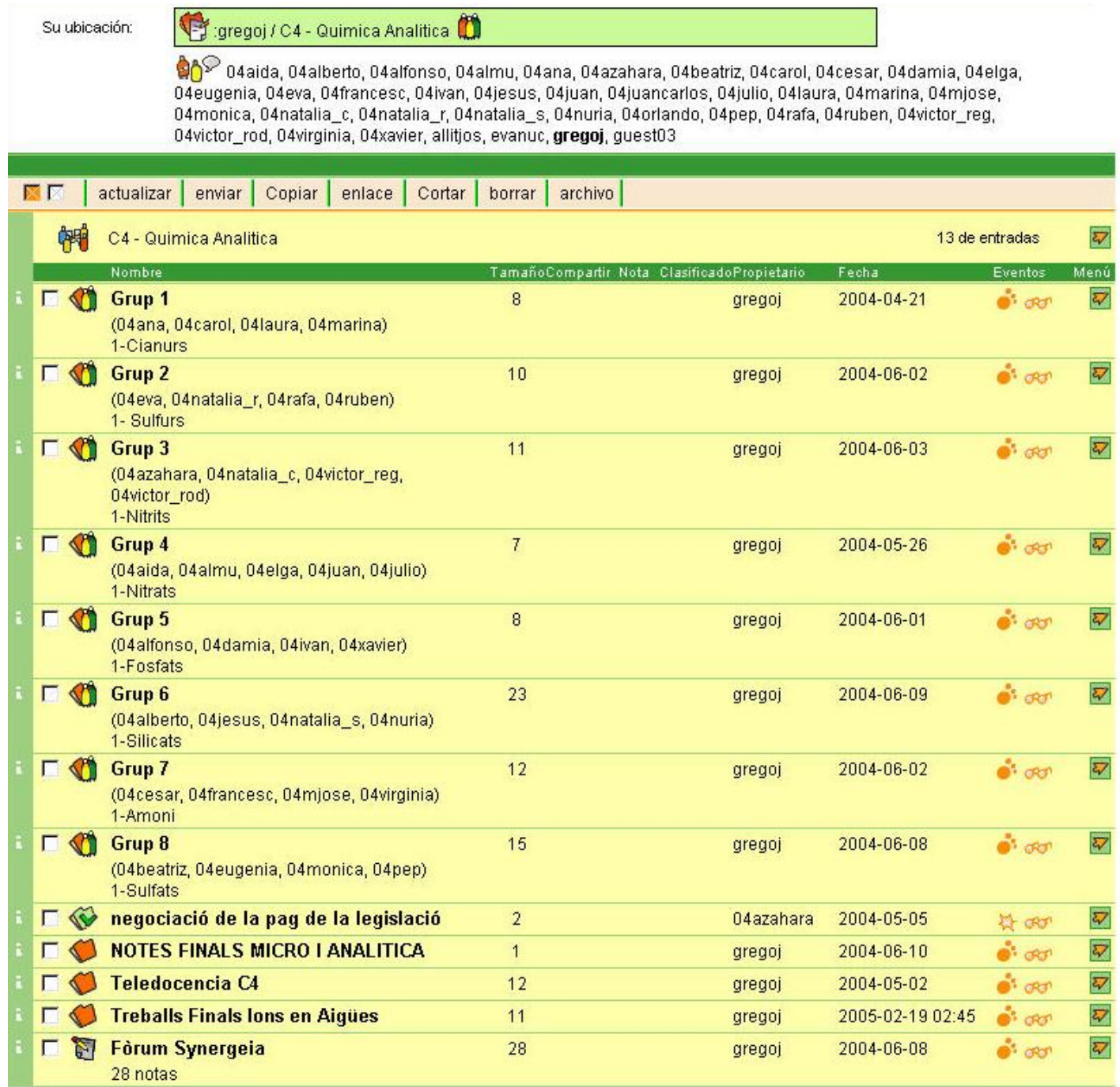

Figura 2. Interior de la carpeta del curs "C4-Química Analítica", amb les 8 carpetes de grup cooperatiu, altres carpetes amb informació per a l'alumnat i el fòrum del curs. 
A més, el Synergeia ofereix un sistema d'informació sobre els moviments i canvis de tot tipus per tal que els grups puguin coordinar el seu treball. Altres funcionalitats que complementen el sistema Synergeia són els espais de construcció de coneixements, la pissarra cooperativa on-line i l'opció de negociació, que permet que el projecte final d'un grup d'estudiants no es doni per bo fins que una majoria dels membres el voti positivament.

\section{El Synergeia a I'IES Mercè Rodoreda}

El Synergeia va ser aplicat durant el curs acadèmic 2003-2004 a la unitat didàctica "Anions en aigües" corresponent al Crèdit 4: "Tècniques fisicoquímiques, químiques i microbiològiques d'aigües", del CFGS de Química Ambiental de l'IES Mercè Rodoreda de L'Hospitalet de Llobregat.

Durant les primeres sessions de l'experiència, i amb l'ajut d'uns tutorials creats expressament, es va explicar el funcionament general de l'entorn i es van donar explicacions sobre com crear documents senzills en format de pàgina web (fent servir l'editor gratuït Redactor de Netscape). Un cop l'alumnat estava familiaritzat amb les dues eines, cada grup de treball havia de realitzar el seu projecte cooperatiu. Els grups de treball estaven formats per qua- tre estudiants, dos de cada grup-classe. El projecte cooperatiu consistia en una sèrie de pàgines web sobre determinats aspectes de la presència d'un anió i de l'amoni en aigües (fig. 3).

L'alumnat havia de treballar dins les seves carpetes de grup. La coordinació i comunicació entre els diferents membres d'un grup cooperatiu era especialment important ja que pertanyien a grupsclasse diferents. La comunicació a l'entorn Synergeia es va donar a tres nivells diferents:

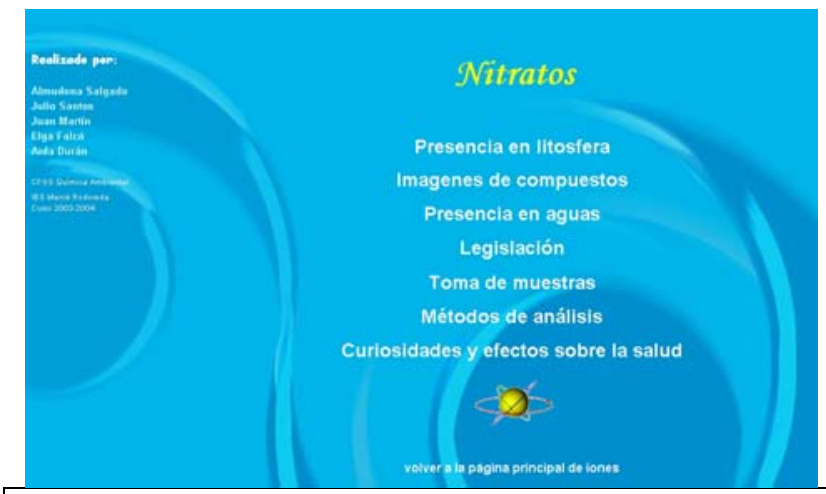

Figura 3. Pàgina principal del projecte sobre nitrats, amb enllaços a les seves diferents seccions.

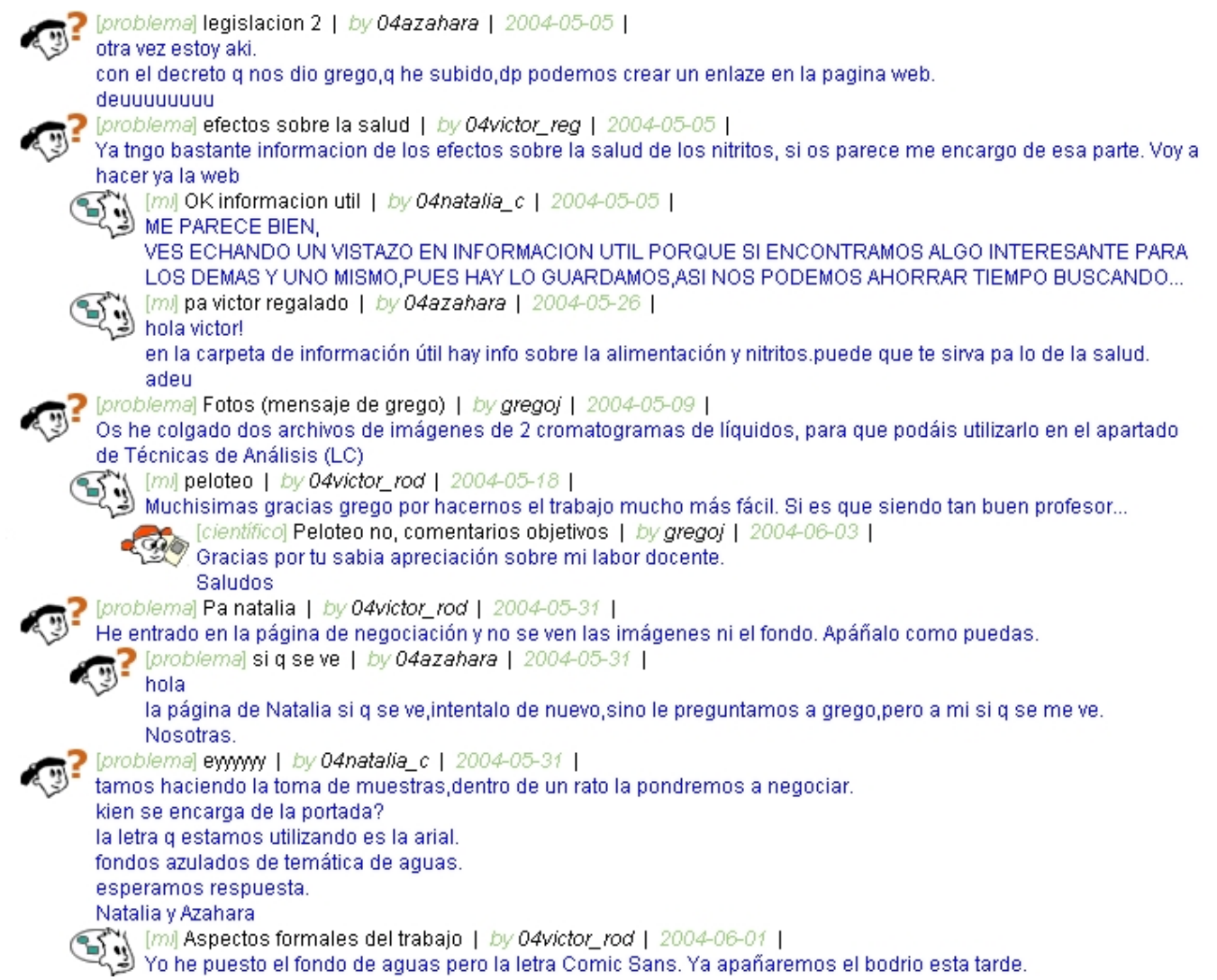

Figura 4. Exemple de discussió dins d'un espai de construcció del coneixement. 
- Interacció asincrònica: Els espais de construcció del coneixement. Aquests espais són fòrums de discussió on s'ha afegit la possibilitat de poder especificar quin és el tipus de contribució que s'està realitzant: "problema" (un estudiant exposa un problema, pregunta o dificultat), "la meva explicació" (un altre estudiant respon a un problema anterior), "explicació científica" (tipus de contribució reservat, generalment, per al professorat), "avaluació" (comentaris per analitzar fins a quin punt el procés avança en la direcció desitjada, si s'estan utilitzant els mètodes adequats, com es pot dur a terme la repartició de responsabilitats...), i "sumari" (síntesi, conclusions o resums de la discussió) (fig. 4).

- Interacció sincrònica: La pissarra cooperativa. Aquesta eina permet que dos o més usuaris puguin treballar simultàniament per crear mapes conceptuals o gràfics amb una finestra de xat per poder coordinar el treball i explicar a la resta de participants en una sessió de pissarra cooperativa què s'està fent (fig. 5). La pissarra cooperativa ofereix a més la possibilitat que qualsevol membre del grup pugui recuperar una sessió anterior de pissarra cooperativa, consultar-la i continuar el gràfic o la discussió en el punt on els seus companys la van deixar.

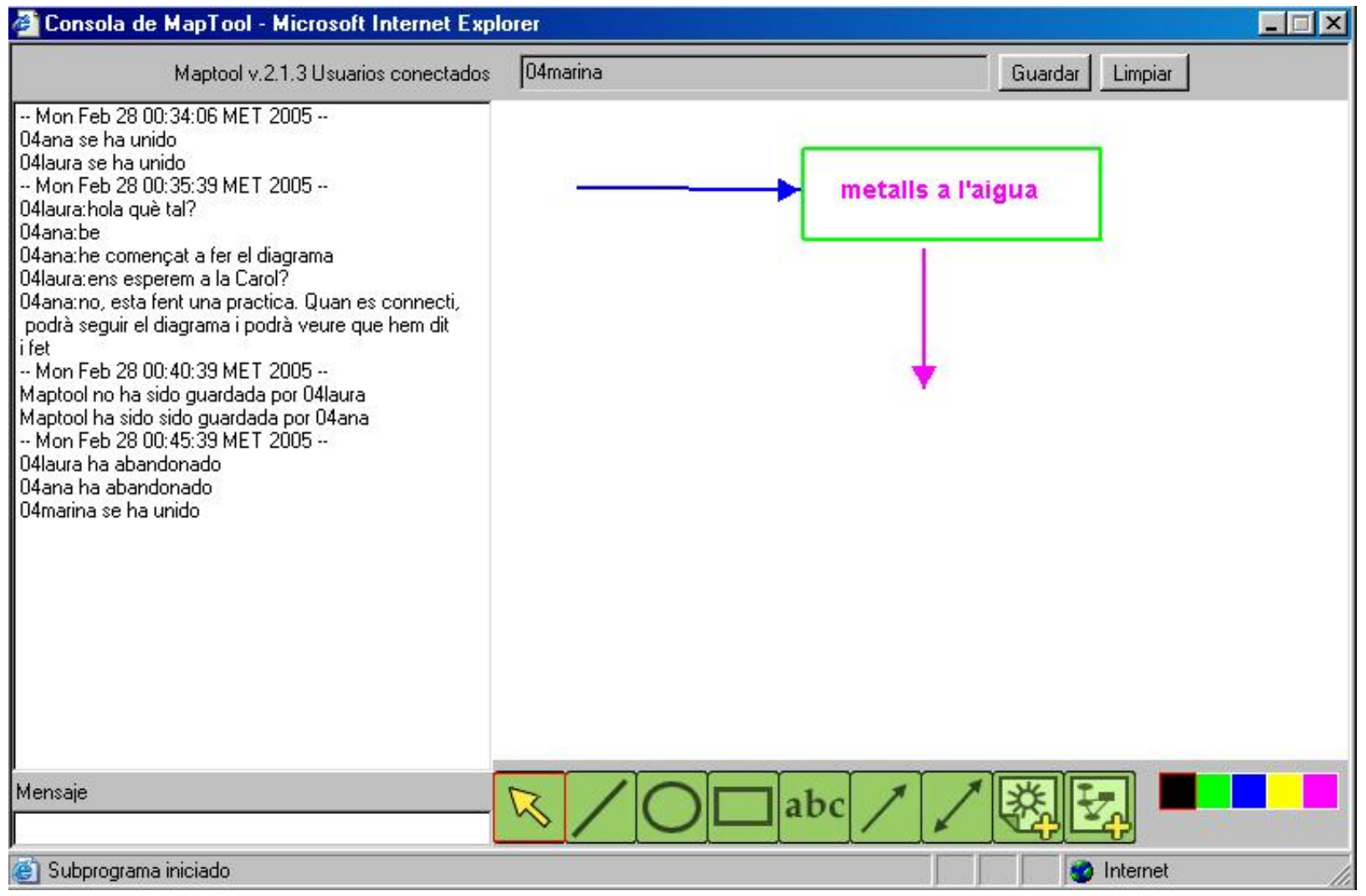

Figura 5. Exemple de sessió de pissarra cooperativa

- Interacció Synergeia-usuaris: Els esdeveniments. Un sistema cooperatiu ha d'informar sobre allò que passa per tal de permetre que els usuaris coordinin el seu treball. El servei d'esdeveniments o els informes d'activitats del Synergeia són un intent de proporcionar als usuaris informacions de les activitats dels altres usuaris, respecte dels objectes de l'espai de treball compartit. Els esdeveniments es produeixen quan un usuari realitza una acció en l'espai de treball compartit, tal com penjar, modificar, llegir o editar un document. Els sistema grava els es- deveniments i presenta els darrers esdeveniments que han tingut lloc en cada objecte per a cada usuari i ho fa mostrant icones diferent, en funció del tipus d'esdeveniment:

$$
\begin{gathered}
\text { (objecte nou), } \\
\text { (objecte editat), } \\
\text { (objecte mogut), }
\end{gathered}
$$

D'aquesta manera, per exemple, un usuari quan es connecta al Synergeia pot saber, mitjançant les 
icones d'esdeveniments, quins esdeveniments han tingut lloc en els espais de treball dels quals ell n'és membre des de la seva darrera connexió al sistema.

Quan algun membre d'un grup cooperatiu considerava que una de les seccions ja estava enllestida, activava el procés de negociació per a aquella subcarpeta. Durant el procés de negociació, tots els membres del grup cooperatiu podien continuar editant els documents que formaven aquella secció i a més disposaven d'un fòrum de discussió on es recollien tots els comentaris sobre l'elaboració del document i el sentit dels vots dels membres del grup: quan s'assolia una majoria de vots positius, aquella subcarpeta corresponent a una secció del seu projecte passava a la pàgina principal del curs, on podia ser consultada, però no editada. El professor podia retornar aquesta subcarpeta amb correccions al grup original per tal que els membres del grup fessin les modificacions oportunes i després activessin un nou procés negociador.

Els treballs finals dels estudiants es poden consultar aquí:

http://www.xtec.net/ giimene2/llicencia/students/ind ex04.html

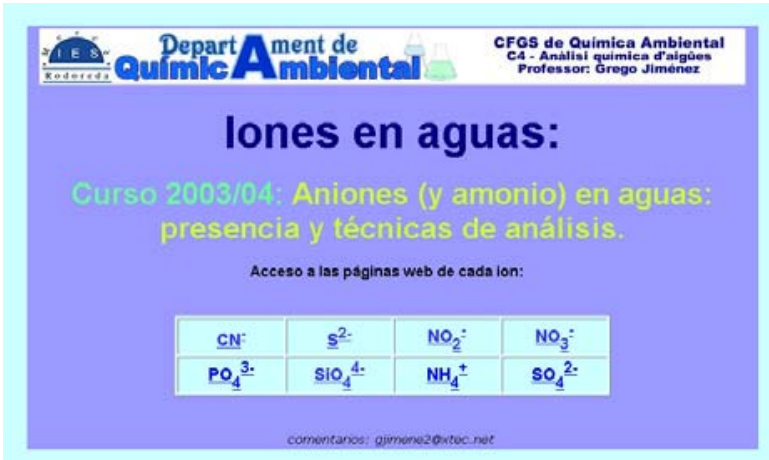

Figura 6. Pàgina principal del curs amb enllaços als treballs

En la realització dels treballs, era molt important que l'alumnat activés tots els enllaços possibles per tal d'unir els seus projectes amb els dels altres grups, fins i tot amb els projectes realitzats durant els dos cursos anteriors amb la plataforma BSCW (cooperació a través del temps). A aquest tipus d'enllaços entre projectes fets per l'alumnat constitueixen un hipertext cooperatiu (Jiménez i Llitjós, 2005b). També era important que els estudiants creessin el major nombre possible d'enllaços a webs externes, d'Internet; per exemple, si en algun apartat d'un dels treballs es feia referència a les al-lèrgies que causava aquell ió, era convenient incloure un enllaç a una pàgina web externa que parlés sobre aquest tema.

El fet que els alumnes haguessin de navegar per Internet no era només per trobar pàgines web adequades per crear enllaços, sinó principalment per cercar la informació necessària per completar els seus treballs. La cerca d'informació a través d'Internet obligava els estudiants a analitzar la informació de les pàgines que trobaven, rebutjant aquelles que contenien errors o informació química incorrecta. La cerca de pàgines web adequades per crear enllaços oferia als alumnes la possibilitat de desenvolupar habilitats grupals, com ara la negociació i la presa de decisions, donat que cada grup cooperatiu havia de decidir i arribar a un acord sobre quins links eren adequats i quins no ho eren.

\section{Avaluació del projecte}

Per tal d'avaluar l'experiència, es van establir tres tipus d'avaluacions:

- Avaluació dels projectes en format de pàgines web, d'acord amb una plantilla comuna en la qual es tenien en compte aspectes funcionals, tècnics i estètics, científics i pedagògics de les pàgines web creades. Aquestes avaluacions van ser realitzades tant pel professor com pels estudiants.

- Autoavaluació del treball de grup: cada estudiant va haver d'avaluar, seguint una escala de 9 graus, l'aportació individual de cada component del seu grup (inclòs ell mateix) en funció de la contribució al treball en equip i a l'acompliment dels acords adoptats pel grup cooperatiu.

- Avaluació, mitjançant una enquesta d'opinió de la plataforma Synergeia com a eina per treballar cooperativament. Aquesta avaluació va ser realitzada per tot l'alumnat.

\section{Conclusions}

El Synergeia és una eina útil i flexible per establir una xarxa de comunicació i cooperació entre l'alumnat i entre alumnat i professorat, i constitueix un format alternatiu a l'aprenentatge cooperatiu tradicional.

La disponibilitat del material i la facilitat de comunicació amb la resta de membres del grup: comunicació en temps real amb la pissarra cooperativa i comunicació diferida a través dels fòrums, augmenta el nivell de motivació, implicació i esforç de l'alumnat.

La realització d'aquest tipus de projectes desenvolupen l'habilitat de l'alumnat per negociar i arribar 
a acords i els fa realitzar cerques d'informació, havent de classificar i seleccionar la de més importància, despertant l'esperit crític respecte de la informació disponible a Internet.

L'alumnat va considerar molt profitós tenir a la seva disposició els materials de treball en qualsevol moment. Per al professorat, l'opció de disposar d'una visió general de les accions de cada estudiant es considera com a un avantatge molt important i que, en combinació amb altres tècniques, facilita l'avaluació del component individual en un treball de grup.

\section{Agraïments}

Aquesta comunicació forma part d'un projecte d'investigació del grup ECEM de la Universitat de Barcelona que Gregorio Jiménez desenvolupa gràcies a una llicència retribuïda concedida pel Departament d'Educació de la Generalitat de Catalunya (DOGC núm.: 4182 de 26.7.2004).

\section{Tutorials}

Tutorials per a fer pàgines web senzilles amb el Redactor de Netscape: http://www.xtec.net/ gjimene2/llicencia/tutorials/red actor-bscw/index.htm

Tutorials del Synergeia per al professorat: http://www.xtec.net/ gjimene2/llicencia/tutorials/pro fessorat.htm

Guies d'ús del Synergeia per a l'alumnat: http://www.xtec.net/ giimene2/licencia/tutorials/alu mnat.htm

\section{Bibliografia}

Jiménez,G.; Llitjós,A (2005a). BSCW: Trabajo cooperativo on-line en la clase. Quark: http://www.fq.profes.net/apieaula2.asp?id contenid $\mathrm{e}=45567$ (consulta: 30/05/2005).

Jiménez,G.; Llitjós,A. (2005b). Una experiencia sobre hipertexto cooperativo en la clase de química. Revista Iberoamericana de Educación (versió digital). OEl,: http://www.campus-oei.org/revista experiencias95.htm (consulta: 30/05/2005).

Johnson,D.; Johnson,R. (1999). Aprender juntos y solos. Aprendizaje cooperativo, competitivo e individualista. Buenos Aires: Paidós. 